\title{
Simple coulometer for studying protonic conduction in crystals
}

\section{Author: V. Hugo Schmidt}

This is a postprint of an article that originally appeared in Journal of Scientific Instruments in December 1965.

Schmidt, V H. "Simple Coulometer for Studying Protonic Conduction in Crystals." Journal of Scientific Instruments 42, no. 12 (December 1965): 889-890.

http://dx.doi.org/10.1088/0950-7671/42/12/417

Made available through Montana State University's ScholarWorks

scholarworks.montana.edu 


\title{
Simple coulometer for studying protonic conduction in crystals
}

\author{
V. H. SCHMIDT \\ Montana State University, Bozeman, Montana, U.S.A. \\ MS. received 21st June 1965, in revised form 31st August 1965
}

\begin{abstract}
A simple glass coulometer with mercury electrodes was designed to measure the amount of gas evolved upon passing current through single crystals, to determine the extent to which electrical conduction in these crystals is due to protons or other gas-forming ions. It is useful if at least one coulomb can be passed through the crystal in a reasonable time interval. With single crystals of $\mathrm{KH}_{2} \mathrm{PO}_{4}$ and $\mathrm{Li}\left(\mathrm{N}_{2} \mathrm{H}_{5}\right) \mathrm{SO}_{4}$ in this coulometer, the ratio of hydrogen evolution rate to crystal current indicates entirely protonic conduction.
\end{abstract}

\section{Introduction}

Coulometric techniques offer a direct and quite sensitive test for electrical conductivity due to gas-forming ions. Kakiuchi, Komatsu and Kyoya (1951) first applied these techniques to solids by demonstrating protonic conductivity in solid cetyl alcohol. Conduction by protons has since been demonstrated by coulometric methods in ice by Workman, Truby and Hansen (1954) and Decroly, Gränicher and Jaccard (1957), by Maricic, Pravdic and Veksli in lithium sulphate monohydrate (1961) and borax (1962), and by Murphy in cellulose (1963) and ammonium dihydrogen phosphate (1964).

The coulometer here described was designed and first used to study protonic conduction in a $\mathrm{KH}_{2} \mathrm{PO}_{4}$ single crystal (Schmidt 1962). Vanderkooy, Cuthbert and Petch (1964) have observed protonic conduction in $\mathrm{Li}\left(\mathrm{N}_{2} \mathrm{H}_{5}\right) \mathrm{SO}_{4}$ with a slightly different coulometer based on this design. The advantages of this design are low cost, ease of construction and operation, and ease of insertion of single crystals for test. The importance of using flawless single crystals in investigating the nature of bulk conductivity is indicated by the result (Maricic et al. 1962) that pressed powder pellets of borax show conductivity over thirty times as great as single crystals oriented in the direction of easy current flow. Presumably this is due to large surface conductivity at grain boundaries and cracks. In ammonium sulphate (Schmidt 1963) the appearance of only a few cracks in a single crystal causes a large increase in measured conductivity.

This coulometer may prove particularly useful in studying the nature of conductivity in those organic crystals containing hydrogen bonds, which have structures for which both electronic conduction as found in organic semiconductors and protonic conduction may be expected to occur.

\section{Description of apparatus}

The coulometer is shown in figure 1. The crystal is sealed into the male portion of the ground glass joint connecting the two parts of the coulometer. A measured current from a d.c. power supply flows through the mercury electrodes and the crystal. The hydrogen evolved at the cathode bubbles upwards and the volume collected is measured in the burette.

The $\mathrm{KH}_{2} \mathrm{PO}_{4}$ crystal tested in this coulometer was inserted by daubing melted paraffin around its edges to make a plug larger than the inside diameter of the ground glass joint and then heating the joint with resistance wire just enough to allow the plug to be pressed in. Wax with a higher melting point could be used if it is necessary to perform the experiment at an elevated temperature in order to have sufficiently high conductivity. It is essential not to crack the crystal in the sealing process because mercury may flow into the crack and cause a short circuit. Vanderkooy (private communication) has found that cracks in the wax seal often occur as the wax cools and contracts. These cracks were sealed by local remelting with a hot copper wire.

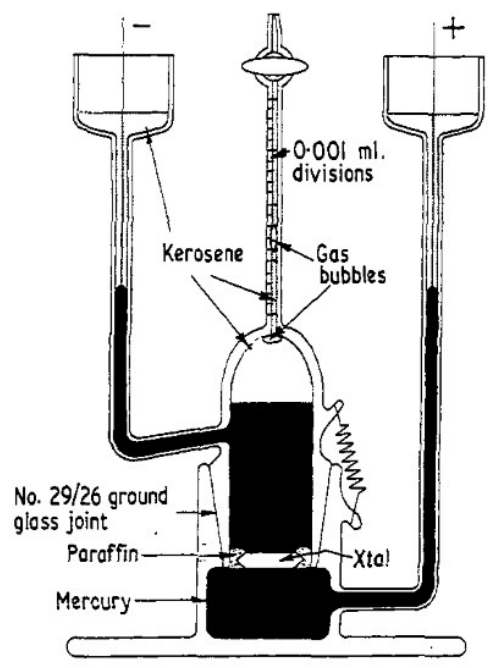

Figure 1. Coulometer.

While filling the apparatus with mercury, the pressure on both sides of the crystal should be kept approximately equal by adding mercury alternately to the two thistle tubes. The air under the crystal must be allowed to escape by tipping the coulometer. After the top crystal surface has been protected by mercury, the desired amount of kerosene or other suitable low-viscosity liquid can be added. Then more mercury is added with the stopcock open until the burette is filled with kerosene; the remaining mercury is added with the stopcock closed. Kerosene in the thistle tubes prevents oxidation and evaporation of the mercury.

If the d.c. power supply-used is not current-regulated significant current fluctuations may occur, and the current should be recorded or preferably integrated to keep track of the charge passed through the crystal. If it is suspected that the crystal may evolve gas spontaneously, as does cellulose (Murphy 1963), the gas evolution rate should be determined with no voltage applied to the mercury electrodes.

To monitor the rate of hydrogen evolution accurately it is 
necessary to tap the coulometer quite vigorously to start the small hydrogen bubbles going upwards through the mercury. The bubbles collect just below the burette. They are introduced into the burette for volume measurement by opening the stopcock for a short time to allow the pressure of the mercury in the thistle tube to force them upward. If a cathetometer is used to measure actual bubble volume and corrections are made for local atmospheric pressure and for pressure due to the liquids in the apparatus, the s.t.p. volume of the bubble can be found with an accuracy to approximately $10^{-4} \mathrm{ml}$. To facilitate analysis of the composition of the gas it might be desirable to incorporate into the coulometer design a provision for storage of all the gas evolved.

\section{Experimental results}

Experimental results obtained by Schmidt (1962) for potassium dihydrogen phosphate and by Vanderkooy, Cuthbert and Petch (1964) for lithium hydrazinium sulphate are shown in figure 2. The coulometer used with potassium

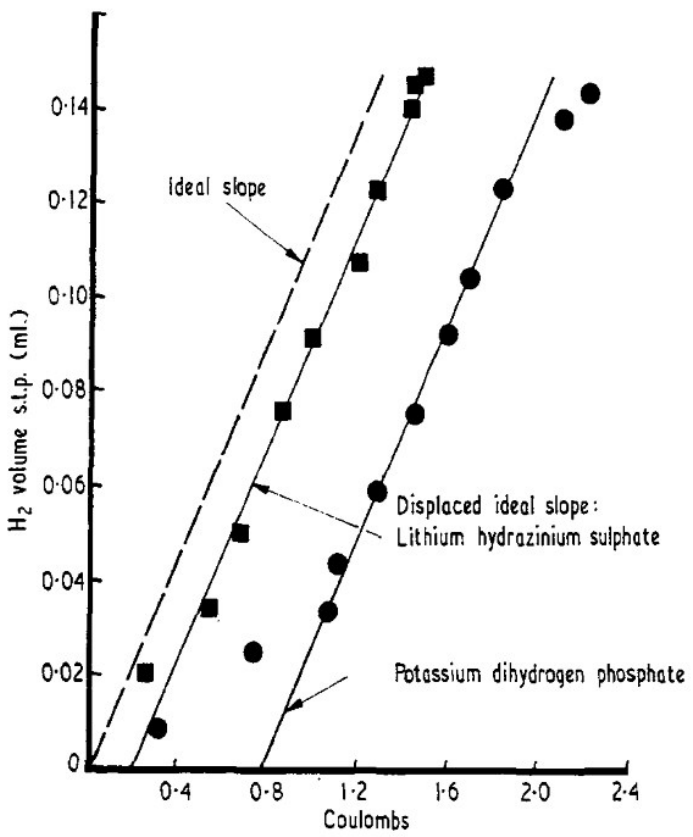

Figure 2. Volume of $\mathrm{H}_{2}$ evolved plotted against charge passed through potassium dihydrogen phosphate and lithium hydrazinium sulphate single crystals.

dihydrogen phosphate was built by Fisher Scientific Company, and for the lithium hydrazinium sulphate study a similar instrument was built at McMaster University. In both experiments the hydrogen evolution rates agreed within experimental error with the value of $0.11613 \mathrm{ml} . \mathrm{H}_{2}$ s.t.p. per coulomb expected for entirely protonic conduction. Initial lags in gas production occurred, corresponding to $0.088 \mathrm{ml} . \mathrm{H}_{2}$ 'lost' for the potassium dihydrogen phosphate work, and $0.019 \mathrm{ml}$. for the lithium hydrazinium sulphate study. The quoted loss for lithium hydrazinium sulphate was from one of the last runs. In the first run Vanderkooy (private communication) observed a loss of about $0.17 \mathrm{ml}$. of $\mathrm{H}_{2}$. The same crystal, mercury and kerosene were used in all runs. Bubbles of $\mathrm{H}_{2}$ ranging from 0.0010 to $0.0320 \mathrm{ml}$. were obtained upon tapping the coulometer, and the lost gas consists partly and perhaps mostly of bubbles of comparable size remaining at the crystal-mercury interface. The interface areas of $0.73 \mathrm{~cm}^{2}$ for potassium dihydrogen phosphate and somewhat over $1 \mathrm{~cm}^{2}$ for lithium hydrozinium sulphate are in approximate proportion to the gas lost. Solution in mercury may account for some of the hydrogen loss, because although no data on this solubility are available, listed solubilities in other metals are all larger than the ratios of $0.028 \mathrm{ml}$. s.t.p. $\mathrm{H}_{2}$ lost per $100 \mathrm{~g} \mathrm{Hg}$ for the first lithium hydrazinium sulphate run and $0.038 \mathrm{ml}$. for the first and only potassium dihydrogen phosphate run. The solubility of $\mathrm{H}_{2}$ in kerosene is appreciablet and bubbles should be measured when first obtained, but the kerosene volume of about $0.25 \mathrm{ml}$. for the first lithium hydrazinium sulphate run is insufficient to account for the hydrogen loss.

For both potassium dihydrogen phosphate and lithium hydrazinium sulphate the final condition of the crystal surfaces was consistent with protonic conduction. The upper (cathode) surfaces were clear and unchanged because the only reaction occurring there was combination of protons diffusing through the crystal with electrons from the mercury to form hydrogen atoms which combined to produce $\mathrm{H}_{2}$. At the lower (anode) surfaces the crystals had to supply electrons to the mercury by means of chemical reactions, and these surfaces became blackened and scaly.

Use of the present coulometer design is practical if one coulomb can be passed through the crystal in a reasonable time, as can be seen from figure 2 .

\section{Acknowledgments}

John Vanderkooy, J. D. Cuthbert and H. E. Petch have kindly supplied me with information about their work with lithium hydrazinium sulphate. The assistance of Gerald $E$. Christiansen with the potassium dihydrogen phosphate experiment is also gratefully acknowledged.

This work was supported by National Science Foundation Grant NSF G-17174 (while author was at Valparaiso University, Valparaiso, Indiana) and by National Institutes of Health Grant GM 12383-01.

\section{References}

DeCroly, J. C., Gränicher, H., and JACCARD, C., 1957, Helv. Phys. Acta., 30, 465-7.

KaKiUChI, Y., Komatsu, H., and KyoYa, S., 1951, J. Phys. Soc. Japan, 6, 321-8.

Maricic, S., Pravdic, V., and Veksli, Z., 1961, Croat. Chem. Acta., 33, 187-95.

1962, J. Phys. Chem. Solids, 23, 1651-9.

MurPhy, E. J., 1963, Canad. J. Phys., 41, 1022-35.

— 1964, J. Appl. Phys., 35, 2609-14.

Schмidt, V. H., 1962, Bull. Amer. Phys. Soc., 7, 440.

1963, J. Chem. Phys., 38, $2783-4$.

VANDERKoOY, J., Cuthbert, J. D., and Petch, H. E., 1964, Canad. J. Phys., 42, 1871-8.

Workman, E. J., Truby, F. K., and Hansen, W. D., 1954, Phys. Rev., 94, 1073.

$\uparrow$ The author is grateful to the referee for pointing out this fact. 